\title{
Functional-Anatomic Correlates of Memory Retrieval That Suggest Nontraditional Processing Roles for Multiple Distinct Regions within Posterior Parietal Cortex
}

\author{
Benjamin J. Shannon ${ }^{1}$ and Randy L. Buckner ${ }^{1,2,3,4}$ \\ ${ }^{1}$ Division of Biology and Biomedical Sciences and 2Departments of Anatomy and Neurobiology and Radiology, Washington University School of Medicine, \\ and ${ }^{3}$ Department of Psychology, Washington University, St. Louis, Missouri 63130, and ${ }^{4}$ Howard Hughes Medical Institute, St. Louis, Missouri 63130
}

\begin{abstract}
Current theories of posterior parietal cortex (PPC) function emphasize space-based attention and motor intention. Imaging studies of long-term memory have demonstrated PPC activation during successful memory retrieval. Here, we explored the relationship between memory processes and classical notions of PPC function. Study 1 investigated old-new recognition using picture and sound stimuli to test whether PPC memory effects were dependent on visuospatial attention. A region lateral to the intraparietal sulcus [inferior parietal lobule complex (IPLC)] and two regions in the medial PPC [precuneus complex (PCC) and posterior cingulate/retrosplenial cortex (pC/Rsp)] showed strong retrieval success effects for both picture and sound stimuli. Study 2 explored a recognition task with varied response contingencies to investigate whether these retrieval success effects are dependent on motor intentions. In one condition, subjects responded to both old and new items. In two other conditions, subjects responded only to old or only to new items. IPLC, PCC, and pC/Rsp continued to show retrieval success effects with similar magnitudes for all response contingencies, including a condition in which no responses were made to old items. In a third study, IPLC and PCC activity was modulated at retrieval based on levels of processing at study, suggesting sensitivity to memory demands. These studies demonstrate that retrieval success effects in lateral and medial PPC regions are not affected by manipulations predicted by classical theories of PPC function but can be modulated by memory-related manipulations. PPC regions thus have prominent response properties associated with memory, which may arise through interactions with medial temporal cortex.
\end{abstract}

Key words: fMRI; memory; parietal; cognitive; learning; attention; motor

\section{Introduction}

The function of posterior parietal cortex (PPC) has been characterized in terms of space-based attention and motor intention. Lesions to parietal cortex can result in neglect or apraxia, deficits of attending to space, and planning motor movements (Heilman and Gonzalez Rothi, 1993; Mesulam, 1999). Functional imaging studies of attention shifts (Corbetta et al., 1998), delayed saccades (Sereno et al., 2001), and reaching and grasping (Culham et al., 2003) all report activity in PPC during these tasks. Single-unit recordings from $\mathrm{PPC}$ in monkeys are consistent with a role in space-based attention and motor planning (Colby and Goldberg, 1999; Andersen and Buneo, 2002). The lateral intraparietal (LIP) area, for example, shows response properties that track attended spatial locations and saccade targets (Snyder et al., 1998; Bisley and Goldberg, 2003). These results support a role for PPC in

Received July 1, 2004; revised Sept. 28, 2004; accepted Sept. 29, 2004.

This research was supported by the Howard Hughes Medical Institute, the James S. McDonnell Foundation Program in Cognitive Neuroscience, and National Institute of Mental Health Grant MH57506. We thank Larry Snyder, Steven Petersen, and Bradley Schlaggar for helpful discussions. Amy Sanders and Kate $0^{\prime}$ Brien assisted with data collection. Avi Snyder and Fran Miezin provided technical assistance, and David Van Essen provided Caret software.

Correspondence should be addressed to Randy L. Buckner, Campus Box 1125, Washington University, 1 Brookings Drive, St. Louis, M0 63130. E-mail: rbuckner@artsci.wustl.edu.

DOI:10.1523/JNEUROSCI.2625-04.2004

Copyright $\odot 2004$ Society for Neuroscience ～0270-6474/04/2410084-09\$15.00/0 representing locations of stimuli and allocating attention or directing motor plans to their position.

In contrast to classical models of PPC function, recent functional imaging studies of memory have identified PPC regions that activate more when subjects recognize old items compared with identification of new items. Parietal retrieval success effects occur across a wide range of retrieval tasks, including recognition of words (Konishi et al., 2000) and faces (Henson et al., 2002; Leube et al., 2003). Effects have been elicited during rememberknow paradigms (Henson et al., 1999; Wheeler and Buckner, 2004) as well as during retrieval tasks requiring simultaneous ratings of retrieval confidence (Henson et al., 2000). Moreover, PPC regions modulate based on subjects' perception that information is old, with increased activity when new items are endorsed as old (Wheeler and Buckner, 2003) and decreased activity when old items are mistaken as new (Wheeler and Buckner, 2003; Kahn et al., 2004). Event-related potential studies have also consistently noted retrieval success effects over left parietal scalp electrodes that have similar properties to those observed in functional magnetic resonance imaging (fMRI) studies (Rugg and Wilding, 2000).

Retrieval success effects in PPC are not easily reconciled with traditional theories of PPC function that emphasize processes associated with spatial attention and motor intention. This diver- 
gence raises the possibilities that either spatial or motor processing differences have confounded retrieval task designs, or PPC function extends beyond these traditional domains. Previous event-related fMRI studies of old-new recognition have used visual stimuli and have required overt responses, leaving open the first possibility. Some studies have used compound cues that involve nonvisual information but have always included a visual component to the cue (Wheeler and Buckner, 2003). In the context of traditional models of PPC function, one plausible explanation for retrieval success effects is that subjects orient their attention differentially to visually presented old items (Althoff and Cohen, 1999). Alternately, recognition decisions might be confounded by motor planning demands. Old-new decision tasks may be implicitly understood as a "detect old items" task or emphasize confidence in the decision. As a result, motor responses might be stronger to targets than to nontargets. PPC retrieval success effects, by this account, may result from motor planning or differential spatial attention toward old items, rather than supporting a direct contribution to memory retrieval or related decision processes.

\section{Materials and Methods}

The present series of three fMRI studies sought to explore retrieval success effects in the context of traditional models of PPC function. These three studies varied stimulus modality (study 1 ), response contingency (study 2), and level of encoding (study 3). Methods common to all studies are discussed first, followed by specific descriptions of the three separate experiments.

Subjects. Seventy-two subjects between the ages of 18 and 35 participated. All subjects provided informed consent in a manner approved by the Washington University Human Studies Committee and were paid for participation. Twenty-seven subjects (11 males) participated in study 1 (mean age, 22.4 years), 29 (15 males) in study 2 (22.7 years), and 16 (8 males) in study 3 (23.8 years). All subjects were right-handed and were native English speakers with no history of neurological disease. Some subjects were excluded from analysis. For study 1, two subjects were excluded for excessive movement and three for poor task performance. In study 2, three subjects were excluded for poor task performance, one for excessive movement, and one for functional data outliers (more than three SDs from the mean in two separate comparisons). For study 3 , one subject was excluded for outlying functional data. Sample sizes and averages given above do not include these excluded subjects.

Functional MRI procedures. Functional imaging was conducted on a 1.5 tesla Magnetom Vision MRI system (Siemens, Erlangen, Germany). Foam pillows and a thermoplastic facemask were used to minimize head movement. Structural images were acquired first using a sagittal magnetization preparation-rapid acquisition gradient echo (MP-RAGE) T1weighted sequence [repetition time (TR), $9.7 \mathrm{msec}$; echo time (TE), 4 msec; flip angle, $10^{\circ}$; inversion time, $20 \mathrm{msec}$; delay time, $200 \mathrm{msec}$. For all studies, whole-brain functional images (168-mm-thick slices oriented along the transverse plane) were collected using an asymmetric spin-echo echo-planar sequence sensitive to blood oxygen level-dependent (BOLD) contrast (T2*; TR, 2.36-2.5 sec; TE, $37 \mathrm{msec} ; 3.75 \times 3.75 \mathrm{~mm}$ in-plane resolution) (Kwong et al., 1992; Ogawa et al., 1992). The first four images in each run were discarded from functional analysis to allow magnetization to stabilize, but the first image, owing to its T1-weighting, was used to align the data to the high-resolution T1-weighted anatomical image.

Functional MRI data analysis. Preprocessing was performed to reduce noise and prepare the data for regional and exploratory analyses. Functional data were first corrected for odd-even slice intensity differences and then motion corrected using a rigid-body rotation and translation correction (Snyder, 1996). Between-slice timing differences caused by slice acquisition order were adjusted using sync interpolation. Linear slope was removed on a voxel-by-voxel basis to correct for drift. Data were normalized to a mean magnitude value of 1000 and were smoothed using a one-voxel-wide isotropic Hanning filter. Signal magnitudes were obtained in relation to task trials by selectively averaging the BOLD fMRI data (Dale and Buckner, 1997) to compute the mean signal change following each trial type in each voxel. Only trial types with a sufficient number of trials were included in analysis. Data were transformed into the stereotaxic atlas space of Talairach and Tournoux (1988) (using 2 $\mathrm{mm}$ isotropic voxels) to permit across-subject analyses (for detailed description, see Maccotta et al., 2001).

Construction of whole-brain activation maps. Contrasts of interest were regressed against a set of time-lagged (offset by $1 \mathrm{sec}$ ) functions that approximate the range of hemodynamic responses typically encountered (Schacter et al., 1997). Statistical activation maps were then constructed for each condition on a voxel-by-voxel basis using a $t$ statistic (Dale and Buckner, 1997). To determine to what degree activation patterns for one comparison overlapped with those of other comparisons, conjunction activation maps were constructed using a threshold of $p<0.001$ in each contrast.

Hypothesis-driven regional analyses. Hypothesis-driven analyses were performed on regions within PPC identified as modulating based on retrieval success. These PPC regions were defined based on exploratory and conjunction analyses performed on data from study 1 to identify regions that showed HIT>correct rejection (CR) effects without effects of modality. Regions were defined to include voxels within $12 \mathrm{~mm}$ of the seed point, which showed HIT $>C \mathrm{CR}$ effects without picture (PIC) $>$ sound (SND) effects (see Study 1 results). These PPC regions were then carried forward as a priori regions for hypothesis-driven tests in studies 2 and 3.

For regional analysis, magnitude estimates were calculated for each subject and for each condition averaged over the volume of the region. This approach affords considerable power by reducing the number of multiple comparisons and averaging the many voxels within each region, thereby increasing the signal-to-noise ratio. Regional time courses were computed by estimating the signal change for each trial type in each voxel for eight time points after the start of the trial. The signal change for the fixation condition was subtracted from that of each of the other conditions to obtain an estimate of signal change relative to fixation baseline. The mean signal change across all voxels in each region for each condition was then computed. Response magnitude estimates were calculated by subtracting the mean signal corresponding to times 0 and $17.5 \mathrm{sec}$ (representing the baseline) from the mean signal at times 5 and $7.5 \mathrm{sec}$ (representing the peak). The magnitude estimates for each subject were entered into a random-effects model, and specific comparisons were made using ANOVA and $t$ tests.

Behavioral procedures. Visual stimuli were presented using an Apple Power Macintosh G4 (Apple Computers, Cupertino, CA) running PsyScope software (Cohen et al., 1993) and projected (Sharp LCD PGC20XU; Sharp, Mahwah, NJ) onto a screen positioned at the head of the magnet bore. Subjects viewed the screen using a mirror attached to the head coil. Sound items were presented using the same computer, which played sounds to the subjects through headphones (Resonance Technology, Northridge, CA). Responses were recorded on a fiber-optic lightsensitive key press interfaced with a PsyScope button box (Carnegie Mellon University, Pittsburgh, PA).

Study 1: Does visuospatial attention account for retrieval success effects? Memory retrieval was explored using visual and auditory items for the following: (1) to replicate retrieval success effects, (2) to determine whether visuospatial attention can account for retrieval success effects, and (3) to precisely define the anatomic extent of regions demonstrating selective retrieval success effects. During prescan encoding, subjects made preference judgments on a mixed list of pictures and sounds. The encoding task was conducted outside the scanner, resulting in a $30 \mathrm{~min}$ encoding-test delay. During each encoding trial, subjects were shown a picture or played a sound and were asked to subjectively rate how much they liked the item on a scale from one to five. Subjects were not told that a memory test would follow. Two encoding blocks of 156 items were presented with each item appearing twice, with a 1 min break between blocks. Pictures ( $n=156$ ) were color, clip-art style objects (e.g., a picture of a dog); sounds ( $n=156$ ) were natural sounds (e.g., the sound of a dog barking). Subsets of both stimuli types were used previously in the studies by Wheeler et al. (2000) and Wheeler and Buckner (2003, 2004). 
Additional stimuli were gathered from the Internet. No subject saw a picture of an item and also heard its sound during either study or test. Stimulus modality was counterbalanced across subjects, so that half of the subjects saw a picture of a dog, whereas the other half heard barking. During encoding, pictures were presented centrally for $400 \mathrm{msec}$, followed by a fixation crosshair (a small plus sign) for $1960 \mathrm{msec}$. Total trial duration was $2.36 \mathrm{sec}$ for both picture and sound trial types. Pictures ranged in size from 4 to $7^{\circ}$ of visual angle (mean, $5.5^{\circ}$ ). Sounds ranged in length from 0.26 to $1.5 \mathrm{sec}$ (mean, $1.23 \mathrm{sec}$ ). Subjects fixated a crosshair throughout the sound trials.

During the scanned test, subjects performed an old-new recognition task. Intermixed old and new pictures and sounds were sequentially presented; subjects made a right-hand key press to indicate whether each item was old or new. Subjects were instructed to respond quickly and accurately. Presentation timing was identical to the encoding phase. Subjects were presented three runs of the recognition task, each containing 86 trials (TR, $2.36 \mathrm{sec}$ ). The first and last four trials of each run were fixation trials (consisting of a fixation crosshair presented for the length of the trial). The remaining 78 trials in each run were divided into 13 trials of old pictures, 13 old sounds, 13 new pictures, 13 new sounds, and 26 fixation trials. Order of trial types were arranged pseudorandomly to allow for hemodynamic signal extraction here and also in Studies 2 and 3 (Dale and Buckner, 1997; Buckner et al., 1998; Dale, 1999). A passive viewing condition was also imaged, with task presentation order counterbalanced across subjects. Because the passive condition did not reveal any notable effects, it will not be discussed further.

Study 2: Do motor intentions account for retrieval success effects? Study 1 explored retrieval success effects in the absence of salient visuospatial information. Classical views of PPC function also emphasize processes associated with motor intention. In study 2 , response contingencies associated with a recognition decision were manipulated to study the interaction between retrieval success effects and motor preparation and response. Three response contingencies were used. In the "Respond OldNew" condition, subjects pressed one button for old items and a different button for new items. In the "Respond Old" and "Respond New" conditions, subjects pressed only a single button for old or new items, respectively, and made no response to other items. In this manner, retrieval success effects could be explored in the precuneus complex (PCC) under conditions that encouraged motor planning (and enhanced attention) to old items, new items, or both. Specifically, in the Respond New condition, retrieval success effects were explored when the old information was not the response target.

During prescan encoding, subjects viewed 160 words (repeated twice) and decided whether each fit the category of "Abstract" or "Concrete" (Demb et al., 1995). The encoding task was conducted outside the scanner, resulting in a 20-40 min encoding-test delay. For each encoding trial, words appeared centrally, subtending $\sim 5^{\circ}$ of visual angle in black text on a white screen for $500 \mathrm{msec}$, followed by a fixation crosshair for $1860 \mathrm{msec}$

Subjects were then scanned while performing an old-new recognition task in the Respond Old-New, Respond Old, and Respond New conditions. Subjects performed three scan runs, each with a different response contingency. Button assignment in the Respond Old-New condition and the order of each response contingency was counterbalanced across subjects. Fifty-six word lists of 14 items each were constructed and counterbalanced such that new words in one subject became old words in another, and also word lists rotated among conditions. Timing of stimulus presentation was identical to encoding. Each of the three runs contained 92 trials (TR, $2.36 \mathrm{sec}$ ), including four fixation trials at the beginning and end, 28 old items, 28 new items, and 28 additional fixation trials.

Behavioral analyses for recognition accuracy assumed that a nonresponse was a response for the alternative (e.g., no response in the Respond Old condition was a response for new). Analyses thus report recognition accuracy for all conditions but response times for only a subset.

Study 3: direct manipulation of retrieval success effects. Studies 1 and 2 explored retrieval success effects in PCC during manipulations of visuospatial attention and motor intention. As the results will show, retrieval success effects are present across these manipulations suggesting nontraditional response properties within specific regions of PPC. The general-
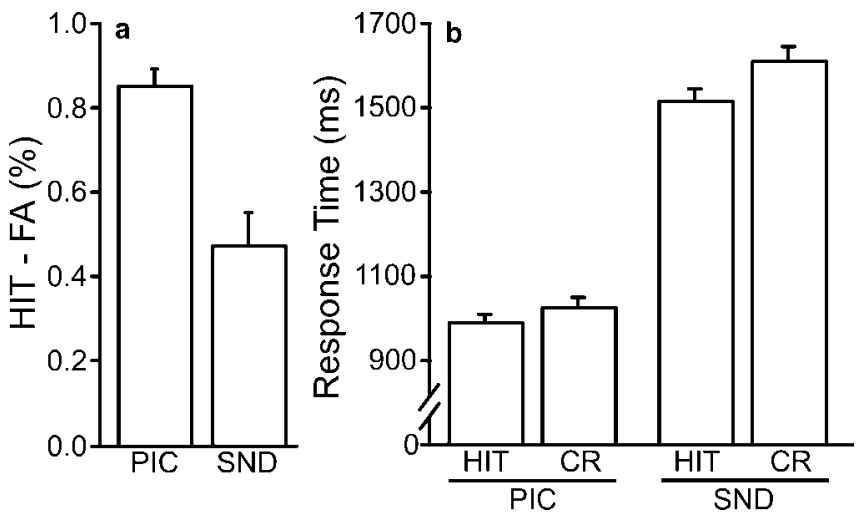

Figure 1. Behavioral results for study 1. $a$, Corrected recognition performance: the percentage of incorrectly identified new items (FA) was subtracted from the percentage of correctly identified old items (HIT) to evaluate performance for each modality. b, Response time. Mean response times for HIT and CR trial types are shown for each modality. For all figures, error bars represent SEM.

ity of the retrieval success effect across the five separate conditions in studies 1 and 2 raises the question of whether any manipulations affect their magnitude. In study 3 , we tested whether the magnitude of retrieval success effects could be affected by manipulations that influence processes associated with memory retrieval, while holding constant the stimulus format and response contingency. As the basis of the manipulation, centrally presented visual words were encoded either with a deep processing task (Abstract-Concrete) or a shallow processing task ("Uppercase-Lowercase") to encourage recollection- and familiarity-based retrieval, respectively (Yonelinas, 2002).

During encoding, subjects performed, using their right-hand, either a letter-case classification task (shallow encoding) or a semantic classification task (deep encoding). Subjects were unaware of the subsequent memory test. For shallow encoding, subjects decided whether the words were in uppercase or lowercase letters. Deep encoding used the same abstract-concrete task as in study 2. Four blocks of encoding (with 50 words each) were performed: two blocks of shallow and two blocks of deep encoding. Words appeared centrally in white on black for $2 \mathrm{sec}$, followed by $500 \mathrm{msec}$ of fixation. Half were uppercase and half lowercase; half were abstract and half concrete. The order of encoding condition was counterbalanced between subjects. Unlike previous studies, encoding was performed while subjects were in the scanner, leading to an $\sim 15 \mathrm{~min}$ encoding-test delay. Encoding data were reported previously (Baker et al., 2001). Stimulus presentation during encoding was similar to that during test.

During scanned test, subjects performed an old-new recognition decision similar to the Respond Old-New condition of study 2. All words were in uppercase. Four trial types were presented: old items from deep encoding, old items from shallow encoding, new items, and fixation trials. Four runs of 104 trials (TR, $2.5 \mathrm{sec}$ ) were presented, each beginning with four fixation trials and containing 25 additional trials of each type. Presentation timing at test was identical to encoding.

\section{Results}

\section{Study 1 behavioral results}

Corrected recognition performance was calculated by subtracting the proportion of new items endorsed as old (FA trials) from the proportion of correctly identified old items (HIT trials). Performance was high for both modalities (Fig. 1a) and greater for pictures than for sounds $\left(t_{(26)}=14.17 ; p<0.001\right)$. This difference in performance was likely attributable to scanner noise, rather than any inherent mnemonic advantage for picture items; an unscanned pilot study showed no significant difference in performance between picture and sound items (data not shown). Response times were faster for pictures than for sounds $\left(F_{(26,3)}=\right.$ 329.11; $p<0.001$ ) (Fig. $1 b$ ). HIT responses were faster than 

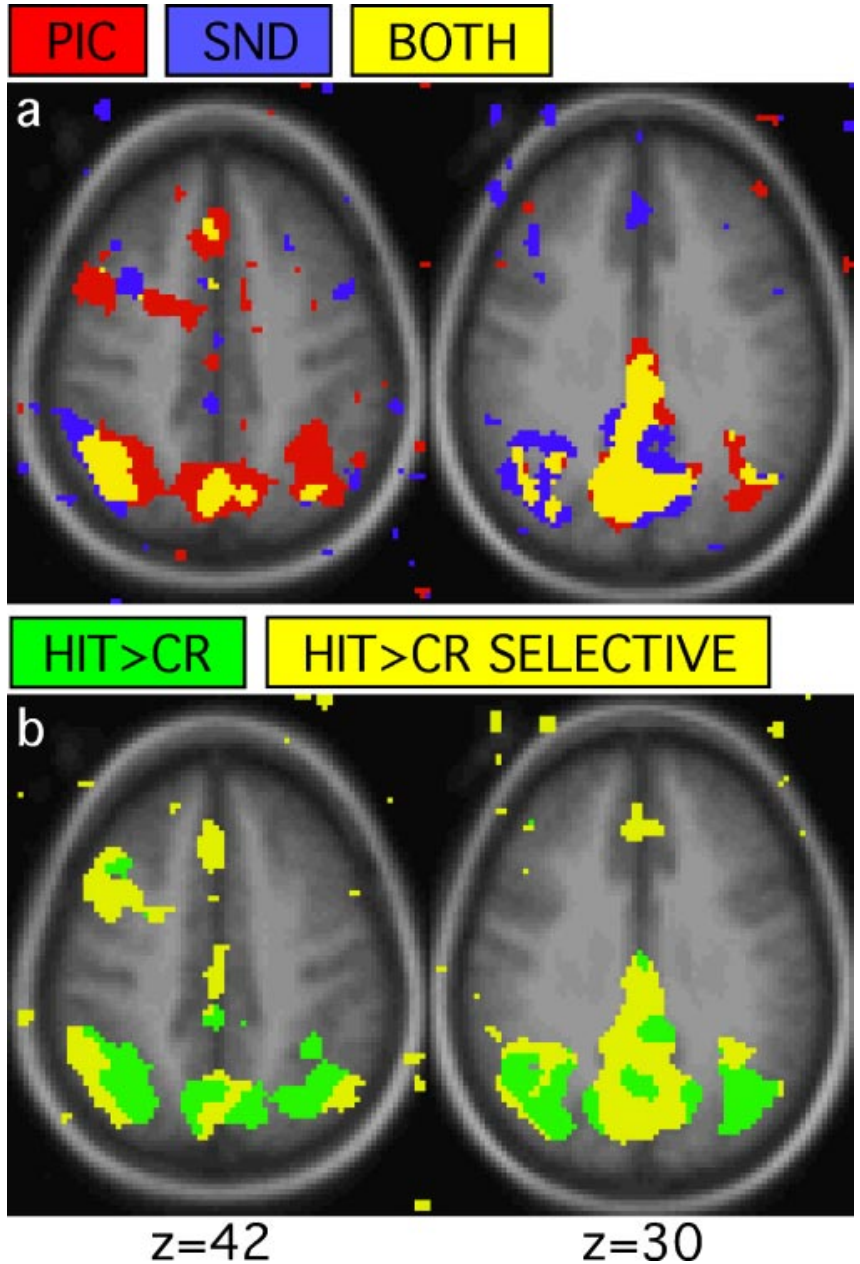

Figure 2. Conjunctions of whole-brain activation maps reveal regions associated with retrieval success. $a$, Conjunction maps generated from HIT $>$ CR for pictures and HIT $>C R$ for sounds reveal regions showing retrieval success effects for pictures (red), sounds (blue), and both (yellow). $b$, Conjunction maps generated from HIT $>C R$ and PIC $>$ SND (CR trials only) contrasts show regions that exhibit retrieval success effects with (HIT $>C R$; green) and without (HIT>CR SELECTIVE; yellow) effects of modality. For all maps, images represent transverse sections with the approximate level taken from the atlas of Talairach and Tournoux (1988). The left hemisphere is displayed on the left. The anatomic backdrop represents the average anatomic image from the subjects included in the study.

correct responses to new items (CR trials) for both modalities $\left(F_{(26,3)}=10.25 ; p<0.001\right)$, with no significant interaction $\left(F_{(26,3)}\right.$ $<1 ; p=0.45)$.

PPC retrieval success effects generalize to auditory stimuli Activation maps were constructed to identify retrieval success effects (HIT minus CR) for both the visual and auditory stimuli. Figure $2 a$ shows the main results. Several regions exhibit retrieval success effects for both pictures and sounds, including prominent activation within PPC, replicating and generalizing previous findings. The locations of activation are consistent with previous reports of PPC retrieval success effects (Henson et al., 1999, 2000, 2002; Konishi et al., 2000; Wheeler and Buckner, 2003, 2004). Modality effects, revealed by direct contrast of the visual and auditory trials, were also prominent. Regions extending through visual cortex and into PPC showed greater activation for retrieval cued by pictures than by sounds (data not shown).

Notably, activation in left and medial PPC exhibited HIT $>$ CR effects without significant effects of modality (Fig. $2 b$ ). Two re-

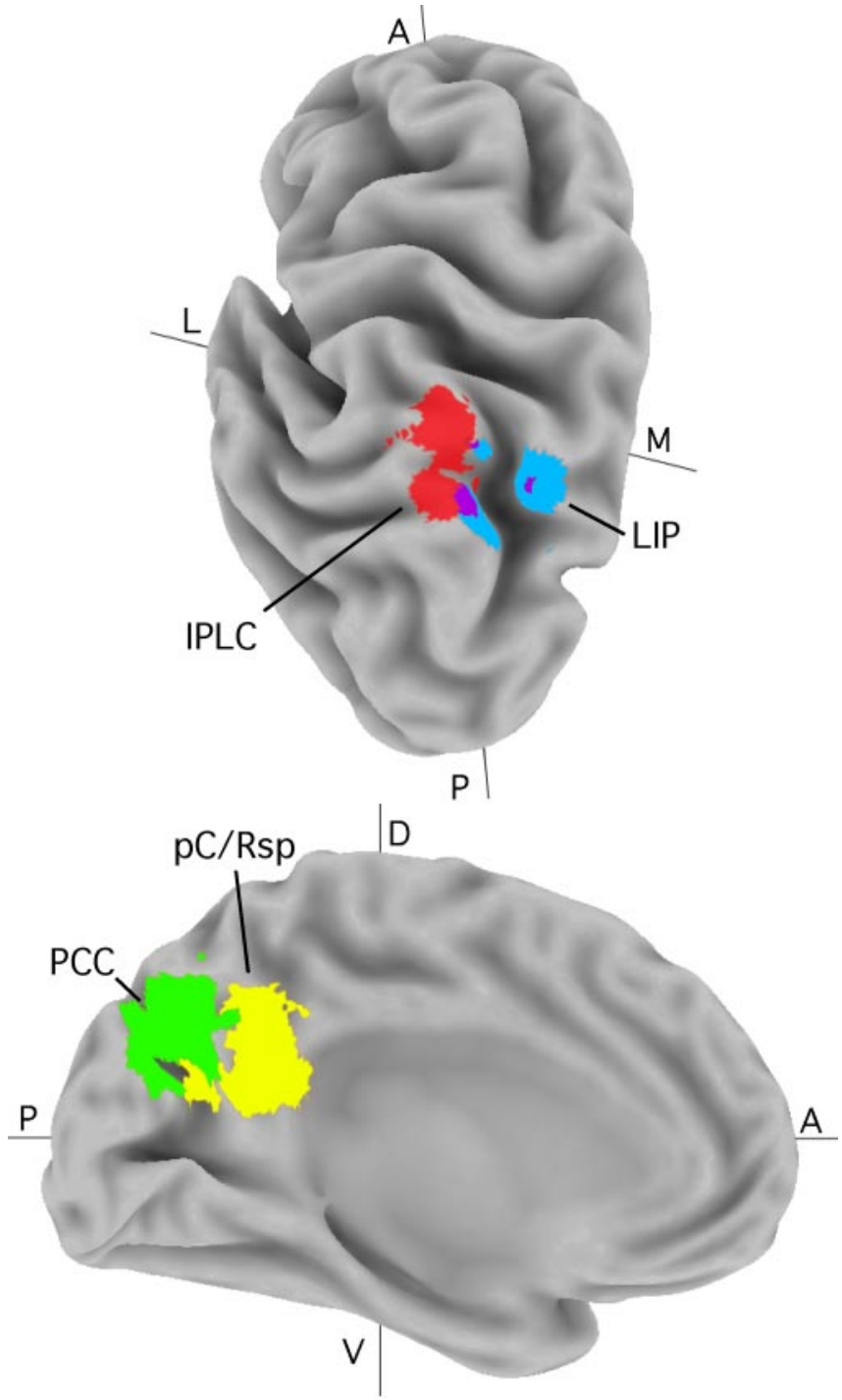

Figure 3. Anatomical location of parietal regions relative to landmarks. Medial (M) and lateral (L) views of PPC show regions IPLC (red), PCC (green), and pC/Rsp (yellow) along with estimates of LIP (blue; based on the study by Sereno et al., 2001) [a spherical region was generated about a peak coordinate exactly contralateral to a reported peak $(-32,-68,46)]$. Images were created using Caret software (Van Essen et al., 2001; Van Essen, 2002). A, Anterior; $P$, posterior; $D$, dorsal; $V$, ventral.

gions were defined centered on these locations labeled the PCC; $\left(-2,-72,30 ; 5.46 \mathrm{~cm}^{3}\right)$ and the inferior parietal lobule complex (IPLC; $-44,-61,42 ; 1.71 \mathrm{~cm}^{3}$ ) (Fig. 3). A third region, anterior to PCC, located in posterior cingulate/retrosplenial cortex, also showed HIT $>C$ R effects without effects of modality ( $\mathrm{pC} / \mathrm{Rsp}$; $-6,-57,26 ; 3.63 \mathrm{~cm}^{3}$ ). Later analyses will focus on IPLC and PCC, but the functional properties of $\mathrm{pC} / \mathrm{Rsp}$ are similar, including both region-of-interest results and appearance in wholebrain activation maps. Figure 4 plots the regional magnitudes of the retrieval success effect for PCC and IPLC, along with data from a control region in extrastriate visual cortex defined from Maccotta et al. (2001) $\left(-36,-72,-12 ; 3.82 \mathrm{~cm}^{3}\right)$. These two regions (IPLC and PCC) serve as the basis for hypothesis-driven analyses in Studies 2 and 3.

\section{Study 2 behavioral results}

Corrected recognition was high and did not vary between conditions $\left(F_{(28,2)}<1 ; p=0.88\right)$, nor did the proportion of Old re- 


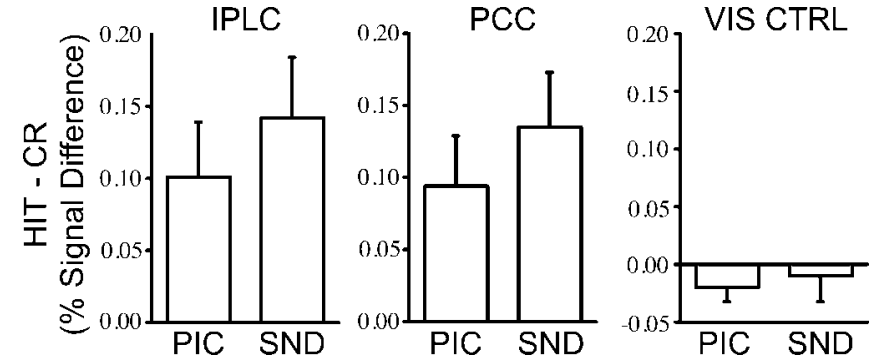

Figure 4. $\quad P P C$ retrieval success effects occur for both picture and sound stimuli. Regional analyses were conducted for IPLC, PCC, and an extrastriate visual region as a control (VIS CTRL). The difference in signal change between correctly identified old (HIT) and new (CR) items is plotted for PIC and SND items for each region. Inferential statistics are not presented for this experiment, because IPLC and PCC were defined based on data from this experiment (Fig. 2b).

sponses $\left(F_{(28,2)}<1 ; p=0.93\right)$, indicating that no criterion shift took place (Fig. 5). Response times did vary across conditions. Correct old items were faster than correct new items $\left(F_{(28,2)}=\right.$ 86.46; $p<0.001)$. Responses were faster in the Respond Old and Respond New conditions, which required only one button press, compared with the Respond Old-New condition, which required a two-choice response discrimination $\left(F_{(28,2)}=34.44 ; p<\right.$ $0.001)$.

\section{PPC retrieval success effects are not dependent on motor intentions}

IPLC and PCC (as defined by the regions from study 1) showed significantly greater activity for correctly identified old items than for correctly identified new items in all conditions, even when no motor responses were made to the old items (all, $p<0.05$ ). Response contingency did not significantly modulate the magnitude of this effect (IPLC, $F_{(28,2)}<1, p=0.99$; PCC, $F_{(28,2)}<1$, $p=0.49)$. A control region in motor cortex, derived from the study by Maccotta et al. $(2001)\left(-36,-26,52 ; 5.48 \mathrm{~cm}^{3}\right)$, did not show retrieval success effects $\left(F_{(28,2)}=0.99 ; p=0.33\right)$ but did show strong modulation consistent with the manipulated response contingencies $\left(F_{(28,2)}=52.16 ; p<0.001\right)$ (Fig. 6). Thus, although the motor contingencies did significantly modulate the motor pathway, IPLC and PCC continued to respond more to HIT than CR even when responses were made only to the CR trials.

It is possible that performance of the Respond Old or Respond New task before the Respond New task might establish a "task set," in which subjects considered old items as targets, although they made no response to those items. To test whether this was the case, we calculated the HIT-CR difference for each region and each response contingency, split by which response contingency each subject first encountered. The results show no support for a task set explanation. In fact, the HIT-CR difference in IPLC and PCC during the Respond New task was greatest when Respond New was the first task performed by the subject.

As a further exploration of retrieval success effects across the three response contingencies, whole-brain activation maps were constructed for HIT minus CR trials for each of the three conditions separately. Figure 7 shows the conjunction among the three maps, revealing medial and lateral PPC activation consistent with the hypothesis-directed analyses described above. Moreover, the localization and extent of the retrieval success effects, here revealed across three conditions that manipulated response contingencies, were highly similar to those revealed in study 1 where modality was manipulated, including activation of both PCC and pC/Rsp on the medial surface (compare Figs. $2 a$ and 7).
Study 3 behavioral results

Corrected recognition performance was higher for words studied under deep than for shallow encoding $\left(t_{(15)}=12.95 ; p<0.001\right)$ (Fig. 8). Both were significantly above chance ( $p<0.001$ for both conditions). For most old-new recognition paradigms, HIT responses are significantly faster than CR responses, confounding retrieval success with effort. One feature of this study is that HIT responses following shallow encoding have a mean response time very similar to CR responses (1013 and $1036 \mathrm{msec}$, respectively). CR responses were significantly slower than HIT responses following deep encoding $\left(t_{(15)}=107.25 ; p<0.001\right)$.

\section{PPC retrieval success effects are influenced by retrieval demands}

IPLC and PCC regions both showed retrieval success effects following both deep and shallow encoding conditions (all, $p<0.05$ ) (Fig. 9). Critically, the magnitude of these effects was significantly greater following deep than shallow encoding, suggesting that memory-related processes at retrieval modulate these specific PPC regions (IPLC, $t_{(15)}=2.39, p<0.05$; PCC, $t_{(15)}=3.28, p<$ $0.01)$. Note that these modulations occurred when only correct (HIT and CR) responses were considered. Thus, the same response was made in each condition to a centrally located target word; only the quality of the mnemonic experience differed.

To further explore modulation at retrieval, a whole-brain activation map was constructed for the contrast of HIT trials following deep encoding to the HIT trials following shallow encoding. Figure 10 shows the results. Medial and lateral PPC regions showed modulation consistent with the hypothesis-directed analyses described above, as well as in pC/Rsp.

\section{Discussion}

Traditional theories of PPC function stress space-based attention and motor intention. Our results identify multiple PPC regions, in particular IPLC and PCC (Fig. 3), of which the response properties track memory retrieval independent of stimulus modality and response contingency. A third region, $\mathrm{pC} / \mathrm{Rsp}$, also showed analogous response properties. These results, in combination with other recent studies of parietal cortex, suggest that conceptions of PPC function should expand beyond attention to external stimuli and motor planning to incorporate higher-order cognitive functions. We discuss first the direct interpretation of the present results followed by the broader implications for models of PPC function.

\section{PPC participates in long-term memory retrieval}

A growing body of data from human functional imaging studies suggests modulation of PPC during memory retrieval (for reviews, see Rugg and Wilding, 2000; Buckner and Wheeler, 2001). The present study identified specific PPC regions that increase activity when old information is identified. Based on their anatomic locations (Fig. 3), they are labeled IPLC and PCC for inferior parietal lobule complex and precuneus complex, respectively. A third region, labeled $\mathrm{pC} / \mathrm{Rsp}$, near posterior cingulate cortex and extending into retrosplenial cortex, was also consistently observed. Beginning with early PET studies of memory, IPLC, PCC, and $\mathrm{pC} / \mathrm{Rsp}$ were found to be active during memoryrelated tasks (Buckner et al., 1996; Fletcher et al., 1996; Habib and Lepage, 2000). Event-related fMRI studies that explicitly contrast HIT with CR items consistently show retrieval success effects in either IPLC, PCC, pC/Rsp, or all three (Henson et al., 1999, 2000; Konishi et al., 2000; McDermott et al., 2000; Daselaar et al., 2001, 

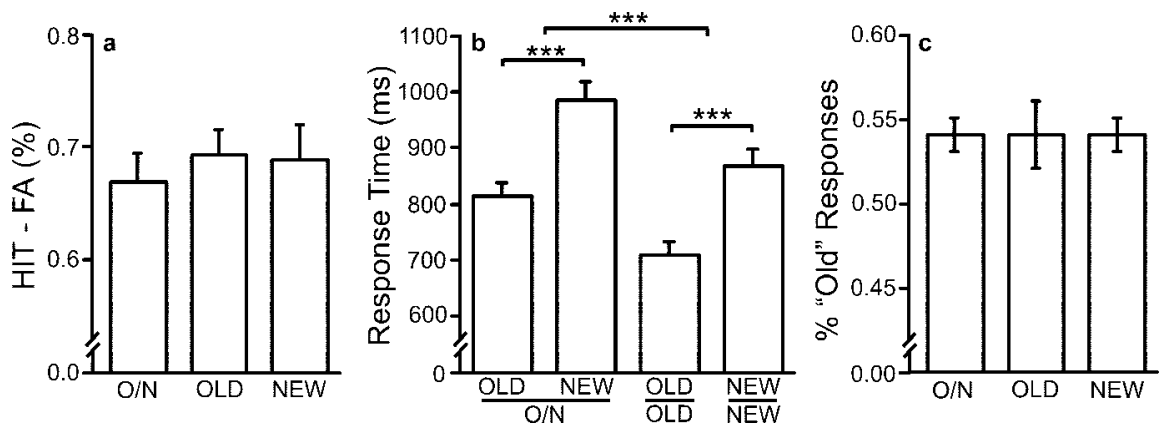

Figure 5. Behavioral results for study 2. $a$, Corrected recognition performance. $b$, Response time. Mean response times for HIT and CR trial types are shown for each trial type that required a response. $c$, The proportion of items identified by subjects as old in each condition. 0/N, Response 0ld/New condition.
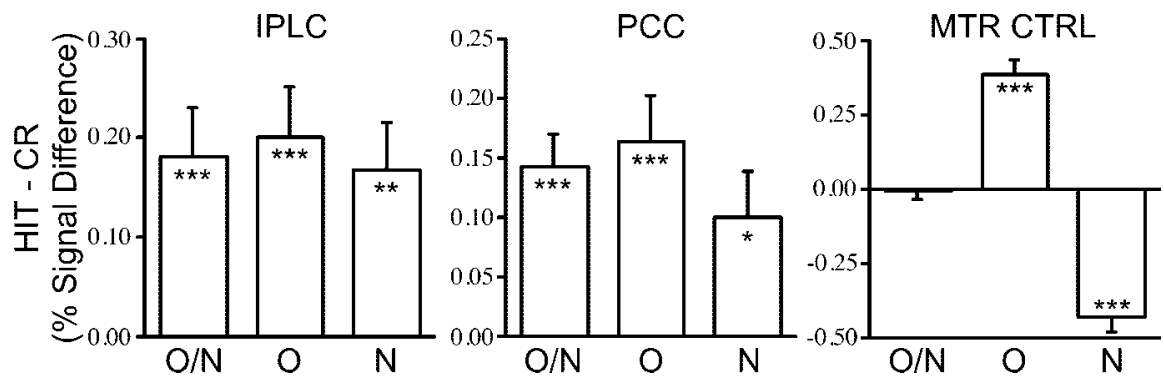

Figure 6. $P P C$ retrieval success effects are independent of response contingencies. Regional analyses were conducted for IPLC, $P C C$, and a motor region as a control (MTR CTRL). The difference in signal change between correctly identified old (HIT) and new $(C R)$ items is plotted for Respond Old/New (0/N), Respond Old (0), and Respond New (N) conditions for each region. IPLC and PCC showed retrieval success effects for all conditions; motor cortex was more active when responses were made, but did not modulate based on the mnemonic status of an item. For all inferential comparisons, asterisks and bars represent different levels of significance: ${ }^{*} p<0.05 ;{ }^{* *} p<0.01 ;{ }^{* * *} p<0.001$.

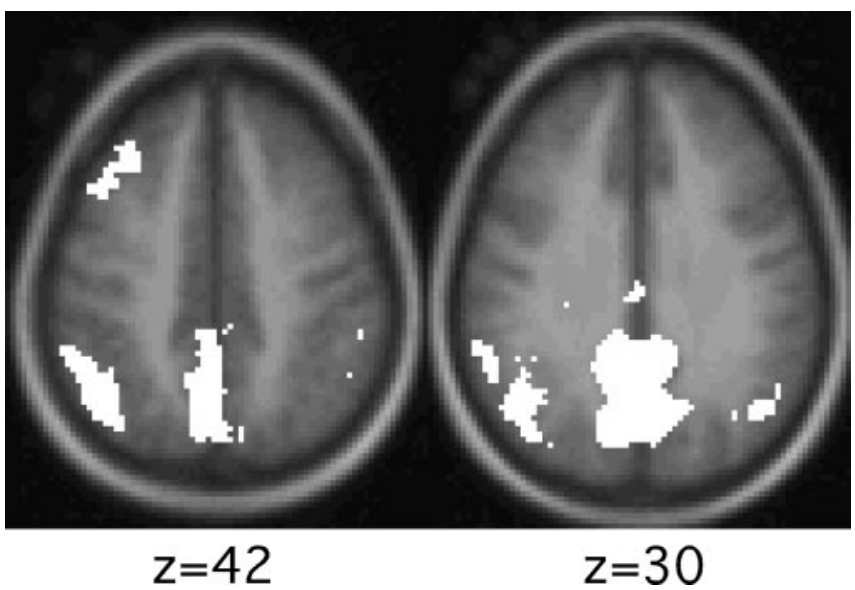

Figure 7. Conjunctions of whole-brain activation maps reveal PPC regions showing retrieval success effects for all response contingencies. Note the similarity between these regions and those shown in Figure 2.

2003; Donaldson et al., 2001a,b; von Zerssen et al., 2001; Leube et al., 2003; Velanova et al., 2003; Wheeler and Buckner, 2003; Herron et al., 2004; Heun et al., 2004; Kahn et al., 2004).

The present results replicate this basic finding across seven separate contrasts and provide additional constraints. First, as noted above, the effect is independent of cue modality (study 1). This result excludes simple visually based attention explanations for the retrieval success effects in PPC. An attention-based model might posit that subjects orient toward the spatial locations of the sounds, which, in the present study, would always come from the same location. Alternately, this result might be explained by suggesting that PPC activity represents attention toward retrieved spatial aspects of the encoding task. Although these explanations cannot be ruled out, one would expect that in both cases the spatial element of the sound items should be less salient; however, the magnitude of the HIT-CR difference is not smaller.

Study 2 provides a second constraint, in that retrieval success effects occur even when responses are made only to new items. This is an important constraint because most retrieval situations implicitly make the old information the target, and PPC modulation might arise because of a response to the default target information. By directly manipulating whether subjects made motor responses to old or new items, the retrieval success effect is shown to be independent of response and also to whether the old items are the sought target (Herron et al., 2004).

Study 3 demonstrates that the magnitude of IPLC and PCC retrieval success effects are influenced by the nature of the retrieval process, with greatest modulation when retrieval is dependent on strong memory traces and/or recollective processes. Previous studies of recollective processes (Henson et al., 1999; Wheeler and Buckner, 2004) have identified regions in left parietal cortex that show greater activity during recollective compared with familiarity-related processes. In both previous reports, these regions have been located on the leftlateral portion of parietal regions showing more general HIT >CR effects (Konishi et al., 2000). The present study confirms this result, using predefined regions. These results are most consistent with a PPC contribution to processes associated with memory retrieval or decision processes that are engaged during memory retrieval tasks.

The PPC regions exhibiting robust retrieval success effects are anatomically similar to regions that show changes to metabolic activity in Alzheimer's disease (Loessner et al., 1995; de Leon et al., 2001; Herholz et al., 2002) (for review, see Buckner, 2004), raising the question of how the two relate. A speculative possibility is that these PPC regions represent direct or indirect cortical targets of medial temporal systems contributing to memory. In macaque, medial temporal regions have major reciprocal connections to PPC, notably including zones near area 7a (Suzuki and Amaral, 1994; Clower et al., 2001; Lavenex et al., 2002) and pC/Rsp (Suzuki and Amaral, 1994; Morris et al., 1999; Kobayashi and Amaral, 2003), and their disruption leads to hypometabolism in both humans and animal models (Reed et al., 1999; Millien et al., 2002). Because pathology associated with Alzheimer's disease affects medial temporal regions and processes, a consequence might be the disruption of PPC regions associated with retrieval success. Alternately, PPC may be directly disrupted as suggested by recent studies of amyloid deposition (Klunk et al., 2004) and longitudinal atrophy in early Alzheimer's disease (Scahill et al., 2002). 

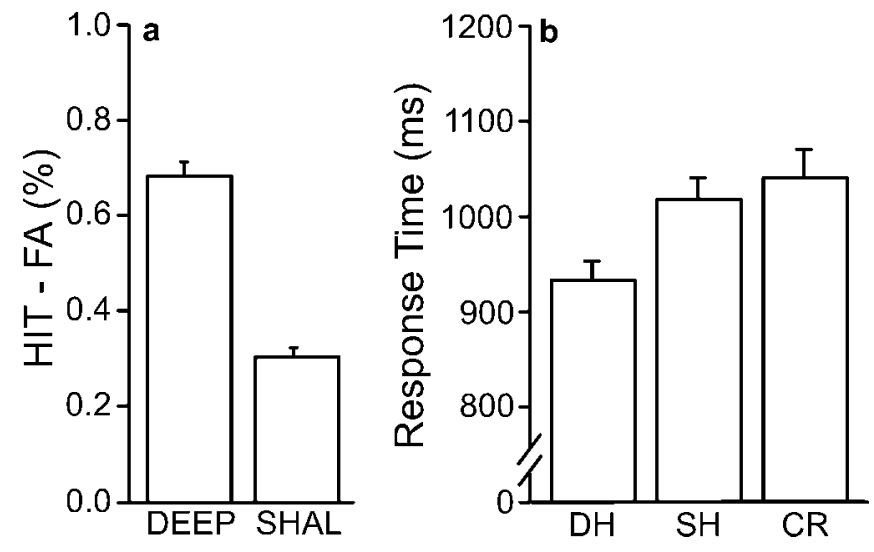

Figure 8. Behavioral results for study 3. $a$, Corrected recognition performance. $b$, Response time. Mean response times are shown for each trial type [DH, HIT following deep study (DEEP); $\mathrm{SH}, \mathrm{HIT}$ following shallow study(SHAL)].

\section{Relation to classical views of PPC function}

Descriptions of PPC function have generally focused on spatial maps, with debate about the nature of information coded within these maps. For example, one view is that PPC represents spatial attention and is tuned to represent the most salient spatial locations (Colby and Goldberg, 1999). An alternative view suggests PPC represents motor intentions (Andersen and Buneo, 2002). Neither of these views captures the data patterns observed during memory retrieval in IPLC and PCC, and thus views of PPC function require expansion or revision.

Nontraditional response properties have begun to emerge in various PPC studies, including response properties within LIP. For example, Platt and Glimcher (1999) noted that LIP activity is related to the expected reinforcement associated with a cue ( $\mathrm{Su}-$ grue et al., 2004). An experiment by Leon and Shadlen (2003) reported LIP neurons of which the activity was related to time perception. An fMRI study by Jiang and Kanwisher (2003) showed PPC involvement in response selection across stimulus modality and response-mapping manipulations. Although each of these results suggests that PPC is involved in a greater range of function than had previously been thought, the fundamental response properties in these studies are within space-based maps and sensorimotor transformations. What is novel about the present results is that PPC modulation is occurring within a higher-level cognitive domain independent of stimulus or response properties.

In considering the relationship of the present results to classical models of PPC function, homologies between PPC areas in human and macaque may provide important constraints. In this regard, it is noteworthy that there is little data from macaque PPC in tasks requiring long-term memory retrieval. One specific possibility raised by the present results is that monkey PPC areas will be identified that show modulation during long-term memory tasks. Alternately, it may be that some areas in human PPC do not have homologs in macaque (Vanduffel et al., 2002). This raises the possibility that IPLC is evolutionarily novel or expanded in humans (Karnath, 2001). One landmark in PPC is monkey LIP (Lewis and Van Essen, 2000) and its putative homolog in humans (Culham and Kanwisher, 2001; Sereno et al., 2001). Figure 3 plots putative human LIP in relation to IPLC identified in this study. IPLC is lateral to LIP and overlaps minimally. For all of these reasons, it seems likely that the PPC regions described here are near to, but distinct from, those studied extensively in monkeys.

Our results provide strong evidence that IPLC, PCC, and pC/
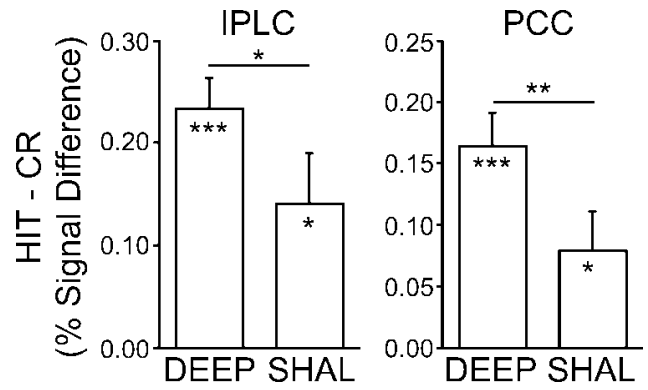

Figure 9. PPC retrieval success effects are influenced by retrieval demands. Regional analyses were conducted for IPLC and PCC. The difference in signal change between correctly recognized old items following deep study (DEEP), following shallow study (SHAL), and correctly rejected new items $(C R)$ is plotted for each region. Both IPLC and PCC showed significant HIT $>$ CR effects, the magnitudes of which were significantly modulated at retrieval dependent on levels of processing at encoding.

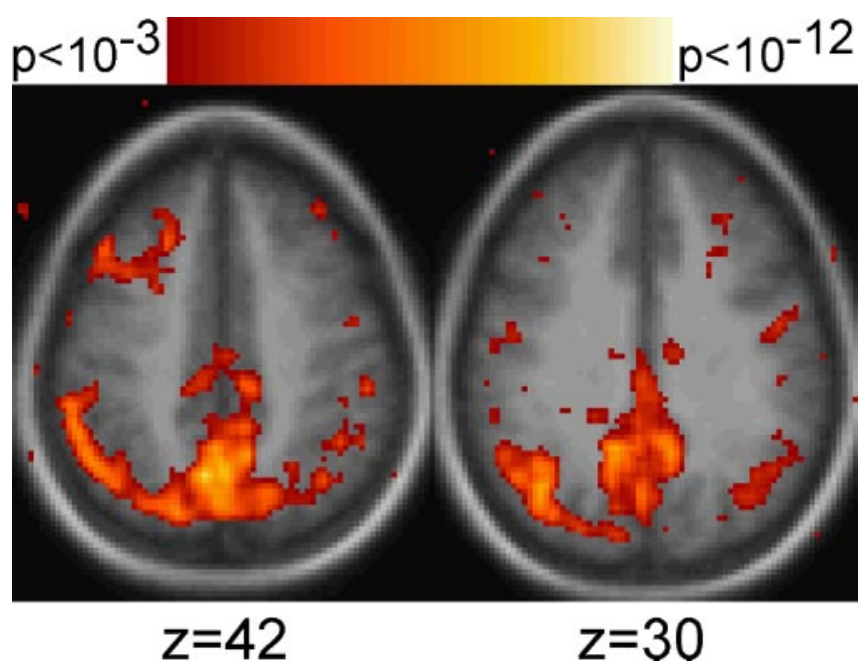

Figure 10. Whole-brain activation maps reveal PPC regions modulating by retrieval demands. Maps show voxels that demonstrate significantly greater activity for deeply studied HIT items versus shallowly studied HIT items.

Rsp perform higher-order cognitive operations associated with memory retrieval. Assuming rough homology between human and macaque, one possibility is that these PPC regions, similar to their neighbors such as LIP, act to transform information between posterior and anterior cortical zones. LIP in macaque, for example, receives projections from extrastriate retinotopic cortex as well as motion-sensitive medial temporal regions (Andersen et al., 1990; Baizer et al., 1991) and projects to motor-related regions such as the anterior intraparietal area (Nakamura et al., 2001) and frontal areas 46 and 8a (Andersen et al., 1990). Monkey inferior parietal lobule has direct reciprocal connections to parahippocampal regions (Andersen et al., 1990; Suzuki and Amaral, 1994; Lavenex et al., 2002) as well as direct projections to area CA1 (Rockland and Van Hoesen, 1999) and receives secondorder input from CA1 via parahippocampus (Clower et al., 2001). Medial parietal regions, particularly retrosplenial cortex, have dense reciprocal connections to the hippocampal formation (Vogt et al., 1992; Suzuki and Amaral, 1994; Morris et al., 1999; Lavenex et al., 2002; Kobayashi and Amaral, 2003). The inferior parietal lobule also has substantial reciprocal connections with several frontal regions, including areas 6, 8a, 11, 12, 45, and 46 (Andersen et al., 1990). IPLC and regions along the medial side of PPC are thus positioned well as an intermediate zone connecting 
frontal regions with representations enabled by the medial temporal lobe memory system. By this view, PPC function may extend to long-term memory processes through its interconnections with the medial temporal lobe.

\section{References}

Althoff RR, Cohen NJ (1999) Eye-movement-based memory effect: a reprocessing effect in face perception. J Exp Psychol Learn Mem Cogn 25:997-1010.

Andersen RA, Buneo CA (2002) Intentional maps in posterior parietal cortex. Annu Rev Neurosci 25:189-220.

Andersen RA, Asanuma C, Essick G, Siegel RM (1990) Corticocortical connections of anatomically and physiologically defined subdivisions within the inferior parietal lobule. J Comp Neurol 296:65-113.

Baizer JS, Ungerleider LG, Desimone R (1991) Organization of visual inputs to the inferior temporal and posterior parietal cortex in macaques. J Neurosci 11:168-190.

Baker JT, Sanders AL, Maccotta L, Buckner RL (2001) Neural correlates of verbal memory encoding during semantic and structural processing tasks. NeuroReport 12:1251-1256.

Bisley JW, Goldberg ME (2003) Neuronal activity in the lateral intraparietal area and spatial attention. Science 299:81-86.

Buckner RL (2004) Memory and executive function in aging and AD: multiple factors that cause decline and reserve factors that compensate. Neuron 44:195-208.

Buckner RL, Wheeler ME (2001) The cognitive neuroscience of remembering. Nat Rev Neurosci 2:624-634.

Buckner RL, Raichle ME, Miezin FM, Petersen SE (1996) Functional anatomic studies of memory retrieval for auditory words and visual pictures. J Neurosci 16:6219-6235.

Buckner RL, Goodman J, Burock M, Rotte M, Koutstaal W, Schacter D, Rosen B, Dale AM (1998) Functional-anatomic correlates of object priming in humans revealed by rapid presentation event-related fMRI. Neuron 20: 285-296.

Clower DM, West RA, Lynch JC, Strick PL (2001) The inferior parietal lobule is the target of output from the superior colliculus, hippocampus, and cerebellum. J Neurosci 21:6283-6291.

Cohen JD, MacWhinney B, Flatt M, Provost J (1993) PsyScope: a new graphic interactive environment for designing psychology experiments. Behav Res Meth Instr Comp 25:257-271.

Colby CL, Goldberg ME (1999) Space and attention in parietal cortex. Annu Rev Neurosci 22:319-349.

Corbetta M, Akbudak E, Conturo TE, Snyder AZ, Ollinger JM, Drury HA, Linenweber MR, Petersen SE, Raichle ME, Van Essen DC, Shulman GL (1998) A common network of functional areas for attention and eye movements. Neuron 21:761-773.

Culham JC, Kanwisher NG (2001) Neuroimaging of cognitive functions in human parietal cortex. Curr Opin Neurobiol 11:157-163.

Culham JC, Danckert SL, DeSouza JF, Gati JS, Menon RS, Goodale MA (2003) Visually guided grasping produces fMRI activation in dorsal but not ventral stream brain areas. Exp Brain Res 153:180-189.

Dale AM (1999) Optimal experimental design for event-related fMRI. Hum Brain Mapp 8:109-114.

Dale AM, Buckner RL (1997) Selective averaging of rapidly presented individual trials using fMRI. Hum Brain Mapp 5:329-340.

Daselaar SM, Rombouts SA, Veltman DJ, Raaijmakers JG, Lazeron RH, Jonker C (2001) Parahippocampal activation during successful recognition of words: a self-paced event-related fMRI study. NeuroImage 13:1113-1120.

Daselaar SM, Veltman DJ, Rombouts SA, Raaijmakers JG, Jonker C (2003) Neuroanatomical correlates of episodic encoding and retrieval in young and elderly subjects. Brain 126:43-56.

de Leon MJ, Convit A, Wolf OT, Tarshish CY, DeSanti S, Rusinek H, Tsui W, Kandil E, Scherer AJ, Roche A, Imossi A, Thorn E, Bobinski M, Caraos C, Lesbre P, Schlyer D, Poirier J, Reisberg B, Fowler J (2001) Prediction of cognitive decline in normal elderly subjects with $2-[(18)$ F]fluoro-2deoxy-D-glucose/positron-emission tomography (FDG/PET). Proc Natl Acad Sci USA 98:10966-10971.

Demb JB, Desmond JE, Wagner AD, Vaidya CJ, Glover GH, Gabrieli JD (1995) Semantic encoding and retrieval in the left inferior prefrontal cortex: a functional MRI study of task difficulty and process specificity. J Neurosci 15:5870-5878.
Donaldson DI, Petersen SE, Buckner RL (2001a) Dissociating memory retrieval processes using fMRI: evidence that priming does not support recognition memory. Neuron 31:1047-1059.

Donaldson DI, Petersen SE, Ollinger JM, Buckner RL (2001b) Dissociating state and item components of recognition memory using fMRI. NeuroImage 13:129-142.

Fletcher PC, Shallice T, Frith CD, Frackowiak RS, Dolan RJ (1996) Brain activity during memory retrieval. The influence of imagery and semantic cueing. Brain 119:1587-1596.

Habib R, Lepage M (2000) Novelty assessment in the brain. In: Memory, consciousness, and the brain: the Tallinn conference (Tulving E, ed), pp 265-277. Pittsburgh: Psychology.

Heilman KM, Gonzalez Rothi LJ (1993) Apraxia. In: Clinical neuropsychology, Ed 3 (Heilman KM, Valenstein E, eds), pp 131-150. New York: Oxford UP.

Henson RN, Rugg MD, Shallice T, Josephs O, Dolan RJ (1999) Recollection and familiarity in recognition memory: an event-related functional magnetic resonance imaging study. J Neurosci 19:3962-3972.

Henson RN, Rugg MD, Shallice T, Dolan RJ (2000) Confidence in recognition memory for words: dissociating right prefrontal roles in episodic retrieval. J Cogn Neurosci 12:913-923.

Henson RN, Shallice T, Gorno-Tempini MI, Dolan RJ (2002) Face repetition effects in implicit and explicit memory tests as measured by fMRI. Cereb Cortex 12:178-186.

Herholz K, Salmon E, Perani D, Baron JC, Holthoff V, Frolich L, Schonknecht P, Ito K, Mielke R, Kalbe E, Zundorf G, Delbeuck X, Pelati O, Anchisi D, Fazio F, Kerrouche N, Desgranges B, Eustache F, Beuthien-Baumann B, Menzel C, et al. (2002) Discrimination between Alzheimer dementia and controls by automated analysis of multicenter FDG PET. NeuroImage 17:302-316.

Herron JE, Henson RN, Rugg MD (2004) Probability effects on the neural correlates of retrieval success: an fMRI study. NeuroImage 21:302-310.

Heun R, Jessen F, Klose U, Erb M, Granath D, Grodd W (2004) Responserelated fMRI of veridical and false recognition of words. Eur Psychiatry 19:42-52.

Jiang Y, Kanwisher N (2003) Common neural substrates for response selection across modalities and mapping paradigms. J Cogn Neurosci 15:1080-1094.

Kahn I, Davachi L, Wagner AD (2004) Functional-neuroanatomic correlates of recollection: implications for models of recognition memory. J Neurosci 24:4172-4180.

Karnath HO (2001) New insights into the functions of the superior temporal cortex. Nat Rev Neurosci 2:568-576.

Klunk WE, Engler H, Nordberg A, Wang Y, Blomqvist G, Holt DP, Bergstrom M, Savitcheva I, Huang GF, Estrada S, Ausen B, Debnath ML, Barletta J, Price JC, Sandell J, Lopresti BJ, Wall A, Koivisto P, Antoni G, Mathis CA, et al. (2004) Imaging brain amyloid in Alzheimer's disease with Pittsburgh Compound-B. Ann Neurol 55:306-319.

Kobayashi Y, Amaral DG (2003) Macaque monkey retrosplenial cortex: II. Cortical afferents. J Comp Neurol 466:48-79.

Konishi S, Wheeler ME, Donaldson DI, Buckner RL (2000) Neural correlates of episodic retrieval success. NeuroImage 12:276-286.

Kwong KK, Belliveau JW, Chesler DA, Goldberg IE, Weisskoff RM, Poncelet BP, Kennedy DN, Hoppel BE, Cohen MS, Turner R, Cheng HM, Brady TJ, Rosen BR (1992) Dynamic magnetic resonance imaging of human brain activity during primary sensory stimulation. Proc Natl Acad Sci USA 89:5675-5679.

Lavenex P, Suzuki WA, Amaral DG (2002) Perirhinal and parahippocampal cortices of the macaque monkey: projections to the neocortex. J Comp Neurol 447:394-420.

Leon MI, Shadlen MN (2003) Representation of time by neurons in the posterior parietal cortex of the macaque. Neuron 38:317-327.

Leube DT, Erb M, Grodd W, Bartels M, Kircher TT (2003) Successful memory retrieval of newly learned faces activates a left fronto-parietal network. Cog Brain Res 18:97-101.

Lewis JW, Van Essen DC (2000) Mapping of architectonic subdivisions in the macaque monkey, with emphasis on parieto-occipital cortex. J Comp Neurol 428:79-111.

Loessner A, Alavi A, Lewandrowski KU, Mozley D, Souder E, Gur RE (1995) Regional cerebral function determined by FDG-PET in healthy volunteers: normal patterns and changes with age. J Nucl Med 36:1141-1149.

Maccotta L, Zacks JM, Buckner RL (2001) Rapid self-paced event-related 
functional MRI: feasibility and implications of stimulus- versus responselocked timing. NeuroImage 14:1105-1121.

McDermott KB, Jones TC, Petersen SE, Lageman SK, Roediger HL (2000) Retrieval success is accompanied by enhanced activation in anterior prefrontal cortex during recognition memory: an event-related fMRI study. J Cogn Neurosci 12:965-976.

Mesulam MM (1999) Spatial attention and neglect: parietal, frontal and cingulate contributions to the mental representation and attentional targeting of salient extrapersonal events. Philos Trans R Soc Lond B Biol Sci 354:1325-1346.

Millien I, Blaizot X, Giffard C, Mezenge F, Insausti R, Baron JC, Chavoix C (2002) Brain glucose hypometabolism after perirhinal lesions in baboons: implications for Alzheimer disease and aging. J Cereb Blood Flow Metab 22:1248-1261.

Morris R, Petrides M, Pandya DN (1999) Architecture and connections of retrosplenial area 30 in the rhesus monkey (Macaca mulatta). Eur J Neurosci 11:2506-2518.

Nakamura H, Kuroda T, Wakita M, Kusunoki M, Kato A, Mikami A, Sakata H, Itoh K (2001) From three-dimensional space vision to prehensile hand movements: the lateral intraparietal area links the area V3A and the anterior intraparietal area in macaques. J Neurosci 21:8174-8187.

Ogawa S, Tank DW, Menon R, Ellermann JM, Kim SG, Merkle H, Ugurbil K (1992) Intrinsic signal changes accompanying sensory stimulation: functional brain mapping with magnetic resonance imaging. Proc Natl Acad Sci USA 89:5951-5955.

Platt ML, Glimcher PW (1999) Neural correlates of decision variables in parietal cortex. Nature 400:233-238.

Reed LJ, Marsden P, Lasserson D, Sheldon N, Lewis P, Stanhope N, Guinan E, Kopelman MD (1999) FDG-PET analysis and findings in amnesia resulting from hypoxia. Memory 7:599-612.

Rockland KS, Van Hoesen GW (1999) Some temporal and parietal cortical connections converge in $\mathrm{CA} 1$ of the primate hippocampus. Cereb Cortex 9:232-237.

Rugg MD, Wilding EL (2000) Retrieval processing and episodic memory. Trends Cogn Sci 4:108-115.

Scahill RI, Schott JM, Stevens J, Rossor MN, Fox NC (2002) Mapping the evolution of regional atrophy in Alzheimer's disease: unbiased analysis of fluid-registered serial MRI. Proc Natl Acad Sci USA 99:4703-4707.

Schacter DL, Buckner RL, Koutstaal W, Dale AM, Rosen BR (1997) Late onset of anterior prefrontal activity during true and false recognition: an event-related fMRI study. NeuroImage 6:259-269.

Sereno MI, Pitzalis S, Martinez A (2001) Mapping of contralateral space in retinotopic coordinates by a parietal cortical area in humans. Science 294:1350-1354.

Snyder AZ (1996) Difference image vs. ratio image error function forms in PET-PET realignment. In: Quantification of brain function using PET (Bailey D, Jones T, eds), pp 131-137. San Diego: Academic.

Snyder LH, Grieve KL, Brotchie P, Andersen RA (1998) Separate body- and world-referenced representations of visual space in parietal cortex. Nature 394:887-891.

Sugrue LP, Corrado GS, Newsome WT (2004) Matching behavior and the representation of value in the parietal cortex. Science 304:1782-1787.

Suzuki WA, Amaral DG (1994) Perirhinal and parahippocampal cortices of the macaque monkey: cortical afferents. J Comp Neurol 350:497-533.

Talairach J, Tournoux P (1988) Co-planar sterotaxic atlas of the human brain. New York: Thieme.

Vanduffel W, Fize D, Peuskens H, Denys K, Sunaert S, Todd JT, Orban GA (2002) Extracting 3D from motion: differences in human and monkey intraparietal cortex. Science 298:413-415.

Van Essen DC (2002) Windows on the brain. The emerging role of atlases and databases in neuroscience. Curr Opin Neurobiol 12:574-579.

Van Essen DC, Drury HA, Dickson J, Harwell J, Hanlon D, Anderson CH (2001) An integrated software system for surface-based analyses of cerebral cortex. J Am Med Inform Assoc 41:1359-1378.

Velanova K, Jacoby LL, Wheeler ME, McAvoy MP, Petersen SE, Buckner RL (2003) Functional-anatomic correlates of sustained and transient processing components engaged during controlled retrieval. J Neurosci 23:8460-8470.

Vogt BA, Finch DM, Olson CR (1992) Functional heterogeneity in cingulate cortex: the anterior executive and posterior evaluative regions. Cereb Cortex 2:435-443.

von Zerssen GC, Mecklinger A, Opitz B, von Cramen DY (2001) Conscious recollection and illusory recognition: an event-related fMRI study. Eur J Neurosci 13:2148-2156.

Wheeler ME, Buckner RL (2003) Functional dissociation among components of remembering: control, perceived oldness, and content. J Neurosci 23:3869-3880.

Wheeler ME, Buckner RL (2004) Functional-anatomic correlates of remembering and knowing. NeuroImage 21:1337-1349.

Wheeler ME, Petersen SE, Buckner RL (2000) Memory's echo: vivid remembering reactivates sensory-specific cortex. Proc Natl Acad Sci USA 97:11125-11129.

Yonelinas AP (2002) The nature of recollection and familiarity: a review of 30 years of research. J Mem Lang 46:441-517. 